\title{
THE AFFECT HEURISTIC IN EARLY JUDGMENTS OF PRODUCT INNOVATIONS
}

\author{
Short Title \\ USE OF THE AFFECT HEURISTIC
}

This is the pre-peer reviewed version of the following article: King, J., \& Slovic, P. (2014). The affect heuristic in early judgments of product innovations. Journal of Consumer Behaviour, 13, 411-428, which has been published in final form at doi: 10.1002/cb.1491. This article may be used for noncommercial purposes in accordance with Wiley Terms and Conditions for Self-Archiving.

\author{
Jesse King (Corresponding Author) \\ Oregon State University, Cascades \\ 2600 NW College Way \\ Bend, OR 97701 \\ Jesse.King@osucascades.edu \\ 541.322 .3174 \\ Paul Slovic \\ Decision Research \\ University of Oregon, Department of Psychology \\ 1201 Oak Street, Suite 200 \\ Eugene, OR 97401 \\ pslovic@uoregon.edu \\ 541.485 .2400
}

\section{Biographies}

Jesse King is an assistant marketing professor at Oregon State University, Cascades. Dr. King studies affective decision making, new product development, innovation and marketplace deception. Jesse has industry marketing research experience in new product development and industrial design consulting. He has received research awards from both the American Marketing Association and the Academy of Management.

Paul Slovic is a full psychology professor at the University of Oregon and is founder and president of Decision Research. Paul studies human judgment, decision making, and risk analysis. He and his colleagues worldwide have developed methods to describe risk perceptions and measure their impacts on individuals, industry, and society. He publishes extensively and serves as a consultant to industry and government. Dr. Slovic is a past President of the Society for Risk Analysis and received its Distinguished Contribution Award. He also received the Distinguished Scientific Contribution Award from the American Psychological Association and has received two honorary doctorates. 


\title{
THE AFFECT HEURISTIC IN EARLY JUDGMENTS OF PRODUCT INNOVATIONS
}

\begin{abstract}
According to the affect heuristic, people often rely upon their overall affective impression of a target to form judgments of risk. However, innovation research has largely characterized risk perception as a function of what the consumer knows rather than how they feel. In three studies, this research investigates the use of the affect heuristic in consumer judgments of product innovations. The findings indicate that judgments of risks and benefits associated with product innovations are inversely related and affectively congruent with evaluations of those innovations. Additionally, more affectively extreme evaluations are associated with increasingly disparate judgments of risk and benefit. This research contributes to our theoretical understanding of both consumers' evaluations of innovations and the affect heuristic. Implications and suggestions for future research are also discussed.
\end{abstract}

\section{Keywords}

Affect Heuristic, Judgment and Decision Making, Product Innovation, Risk 


\section{THE AFFECT HEURISTIC IN EARLY JUDGMENTS OF PRODUCT INNOVATIONS}

\section{Introduction}

Tomorrow a cell phone manufacturer will release their newest creation. A flashy model with great new features not found on any other phone in the marketplace today. Undoubtedly, the phone will be promoted using a series of strategic press releases, social media campaigns and colorful advertisements. What processes will consumers use to weigh the potential risks and benefits associated with adopting this innovation?

Existing innovation adoption literature suggests that consumers will proceed through a series of adoption stages described by Rogers (2003). From this perspective, prospective consumers carefully gather and consider information to form a well reasoned, analytical evaluation of the risks and benefits associated with the innovation. While much previous research supports this account, the present research suggests a complementary, affective process to explain how consumers form early judgments of new products.

Marketing practitioners have long maintained an interest in explaining how consumers make decisions regarding innovative products (Hauser et al., 2006). Concurrently, researchers have been working more broadly to understand the role of affect in consumer behavior (Cohen et al., 2008). This work has proved fruitful and substantially advanced our theoretical understanding of how people use affective information (feelings) to inform decision making. Affect here is defined as... Affect is different than moods or specific emotions.... Kahneman (2003) for example, argues that decisions arise from two interrelated, but distinct systems. To arrive at an evaluative 
judgment or decision, an individual may use both an intuitive, experiential decision process (system 1), relying upon heuristics to efficiently process information in conjunction with a more effortful, reasoned, cognitive process (system 2 ) to carefully analyze information at hand. Researchers have found that affect is a central component of both processes, and is used as an input for many judgments (Schwarz and Clore, 1988) because it often provides useful information (Feldman Barrett and Salovey, 2002, Pham and Avnet, 2009).

Although emotion and affective decision processes are acknowledged as important by consumer behavior researchers, the literature investigating innovation adoption decisions has remained focused largely on analytical processes (Wood and Moreau, 2006). The present research addresses this gap by examining how consumers use affective information to determine the risks associated with innovation adoption decisions. Specifically, we present evidence that risk and benefit evaluations regarding innovations are often related because judgments of both attributes are influenced by a consumer's affective response to an innovation. In the following sections, we review previous innovation adoption literature as well as theory surrounding the use of affect in decision making. Then, we present three experimental studies demonstrating consumers' use of an "affect heuristic" in forming evaluations of innovations. Finally, we conclude by discussing the theoretical implications of these findings and offering suggestions for additional research.

\section{Innovation Adoption Processes}

Innovation adoption research has largely centered on predicting the rate of adoption in aggregate rather than individual adoption decisions in isolation (Herzenstein 
et al., 2007). Researchers have approached the question of how consumers adopt innovations from multiple perspectives considering individual characteristics, situational factors and product attributes that promote or inhibit adoption (Hauser, et al., 2006, Rogers, 2003). Various individual differences influence how consumers choose to adopt innovations (Gatignon and Robertson, 1991, Jansson et al., 2011, Manning et al., 1995, Wood and Swait, 2002). For example, a sizeable quantity of research has focused on defining and measuring the concept of consumer innovativeness - a consumer's propensity to adopt new products (Hauser, et al., 2006, Hirschman, 1980). Dispositional innovativeness influences the way in which consumers respond to product attributes and marketing communications (Steenkamp and Gielens, 2003). Other individual difference attributes that have been considered include prior expertise (Moreau et al., 2001) and both dispositional and situational regulatory focus (Herzenstein, et al., 2007).

Other researchers have explored how the decision context influences evaluations of innovations. Alexander et al. (2008) demonstrated that when considering adopting an innovation in the distant future, consumers initially focus on the benefits that the prospective product could provide. As the time to adoption nears, this focus shifts and consumers become more concerned with the practicalities of purchasing and using a product. Evidence of a similar shift in perspective was found by Castaño et al. (2008) who suggested that promotional messaging should transition from a focus on potential outcomes for temporally distant adoption decisions to encouraging consumers to visualize the processes of how they might adopt the product when the decision was close at hand. They also found that the emotions experienced by consumers shift from optimism about a temporally distant adoption to anxiety regarding an adoption decision 
in the near-future. In the current research, we investigate how positive or negative valenced feelings such as these can influence subsequent evaluations of an innovation.

The role of emotions in evaluations of innovations was considered in another set of studies conducted by Wood and Moreau (2006). They found that negative and positive emotions could arise as consumers first learn to use an innovation. Their findings indicated that product demonstrations help to improve the accuracy of novices (but not experienced consumers) in their predictions about how difficult it will be to learn to use a new product. Their research also found evidence that the disconfirmation of complexity expectations as consumers first use innovations can trigger emotions that subsequently influence post trial product evaluations. The present research differs from that of Wood and Moreau (2006) by considering the importance of affect much earlier in the adoption process, as it is elicited in response to the initial presentation of an innovation.

In regards to product attributes, the relative advantage, complexity, trialability and observability of an innovation have all be found to influence the rate of adoption (Rogers, 2003). Additional factors such as affordability, visual comprehensibility, and adaptability have also received some attention (Nakata and Weidner, 2012). The perceived riskiness of an innovation was identified early on as one of the most salient factors thought to influence innovation adoption decisions (Ostlund, 1974, Rogers, 2003, Sheth, 1981). Because innovations are inherently novel, the benefits they may provide are uncertain (or unproven), as are the risks associated with their adoption (Veryzer Jr, 1998). These risks may originate from a myriad of sources including switching costs, social and personal 
disappointment, hidden ownership costs, unknown quality attributes, the potential for physical harm, and uncertainty in service delivery (Ram and Sheth, 1989, Sheth, 1981).

In whatever form, risk perception regarding innovations has been conceptualized largely as an analytical assessment. For example, Ram and Sheth (1989) discuss risk as a barrier to innovation adoption by noting that "consumers, aware of the risks, try to postpone innovation adoption until they can learn more about it” (p. 8). In their recent meta-analysis, Arts et al. (2011) described how models such as Rogers' innovation diffusion theory (2003), the technology acceptance model (Davis, 1989), the theory of reasoned action (Fishbein and Ajzen, 1975, Sheppard et al., 1988) and the theory of planned behavior (Ajzen, 1991) have all been used to explain consumer innovation adoption decisions. In each of these theories, innovation adoption is conceptualized as an uncertainty reduction process (Mahajan et al., 1990, Rogers, 2003). As customers gain an increased understanding of an innovation, they are better able to assess its benefits (Hoeffler, 2003). A key element in this line of thought is that consumers form attitudes through the reduction of uncertainty. While these attitudes are conceptualized as partially affective in nature, their formation occurs through a bottom-up cognitive process in which consumers carefully gather and consider available information, then make a decision. The present research considers an alternative explanation for how consumers form early judgments of product innovations.

\section{Affective Decision Making}

Feelings provide consumers with an important source of information. In a now classic study, Schwarz and Clore (1983) demonstrated that people selectively rely upon their feelings as a source of information when those feelings are perceived to be relevant 
to the judgment at hand. Numerous additional studies (Gorn et al., 1993, Keltner et al., 1993) have substantiated the important informational role of affect in decision making. Pham et al. (2001) applied this feelings-as-information framework to demonstrate differences in reason-based versus affect-based judgments toward advertising. Their findings indicated that affective judgments are often faster, more consistent across individuals, and more predictive of thoughts toward a target than reason-based judgments.

This perspective is also compatible with the somatic marker hypothesis (Bechara et al., 2000, Damasio, 2000, Hinson et al., 2002) which originated from clinical work suggesting that people, in part, make decisions by relying upon emotions arising from the recall of emotionally marked images. The positive and negative markers associated with these images influence the extent to which people prefer one option to another. The influence of these emotions is largely unconscious and occurs automatically as individuals anticipate the consequence of possible decisions.

Affect may arise directly as a person encounters a novel object that elicits an affective reaction or as a consequence of cognitive processing (Duckworth et al., 2002, Schwarz and Clore, 2007). Work by Slovic et al. (2002) has provided evidence that individuals use affect as a heuristic in forming more complex judgments. The "affect heuristic" is based on the idea that when forming a judgment, it is more efficient for people to rely upon their overall affective impression of the object than it is for them to cognitively weigh all available information. Evidence for the affect heuristic has been provided by studies demonstrating that both benefit and risk evaluations of some target can be explained, in particular contexts, by a participant's more general affective 
experience in response to a target (Alhakami and Slovic, 1994, Finucane et al., 2000).

Other research has also shown support for affect as a basis for risk assessment. For example, in their study of the risk-as-feelings hypothesis, Lowenstein et al. (2001) argued that affective reactions can sometimes diverge from cognitive evaluations of risk. In these cases, affect often provides the dominant influence to a variety of judgments.

Because risk perception has been found to be a critical driver of innovation adoption decisions (Ostlund, 1974, Rogers, 2003, Sheth, 1981), it is important to consider how perceptions of risk might be influenced by affect. As discussed above, risk perception regarding innovations has largely been described as a function of what the consumer has learned about the new product (Ram and Sheth, 1989). Certainly this knowledge is important. However, the affect heuristic suggests that how a consumer feels about a product may also determine evaluations of risk (and other attributes).

While both the risks and benefits associated with adopting an innovation are often uncertain, the benefits gained from adopting an innovation are qualitatively different than the risks posed by the adoption. For example, the expected benefits from adopting an electric vehicle (e.g., emissions free transportation) are largely separate from the associated risks (e.g., concerns about long term reliability). In most instances, if risks and benefits are associated to any extent, the benefits of adopting an innovation are likely to be positively related to the risks of adopting the innovation. As Finucane, et al. (2000, p. 3) suggest:

"Whereas activities that bring great benefits may be high or low in risk, activities that are low in benefit are unlikely to be high in risk (if they were, they would be proscribed), suggesting the positive correlation..." 
In a product context, this idea translates into the reality that products that are risky and offer little benefit are unlikely to be successful in the marketplace. However, the work of Alhakami and Slovic (1994) as well as Finucane, et al. (2000) demonstrate that in many situations, people perceive risks and benefits to be inversely (i.e. negatively) related. That is, the greater the perceived risk, the lower the perceived benefit and visa versa. A plausible explanation of this inverse relationship is that the assessment of both risk and benefit are both derived from the same underlying affective response (positive/negative). Consumers draw upon this affective experience and use it to form congruent judgments of other attributes. Positive affect, therefore, promotes a favorable assessment of benefits, and a deflated assessment of risks, whereas disliking produces the opposite pattern. Thus, the inverse relationship between risk and benefit comes to exists in people's minds when they use affect to inform their judgments (Slovic, et al., 2002).

Prior research into the affect heuristic has primarily focused on judgments of the risks and benefits associated with broadly defined hazardous technologies (e.g., food preservatives, nuclear power and pesticides) and activities (e.g., firefighting, air travel and surgery) in reference to how they would impact society as a whole (Alhakami and Slovic, 1994, Finucane, et al., 2000). Participants in these studies had prior knowledge and attitudes about these technologies or activities. What has not been investigated is how the affect heuristic might be used to form evaluations of unfamiliar activities or product innovations. The current research helps to address this gap by investigating how the affect heuristic applies to judgments of new products. Existing research offers mixed evidence regarding how consumers use affect in judgments of novel stimuli. When evaluating novel financial assets Ganzach (2000) found that, even among people who are 
well trained at analyzing stock markets, estimates of the risks and returns associated with unfamiliar stock indexes tend to be negatively related and congruent with their global preferences for the assets. This finding is compelling because the risks and benefits of financial markets objectively should be positively correlated (increasing risk should bring increasing returns). Similarly, Macgregor et al. (2000) investigated the role of imagery and affect in decisions about initial public offerings (IPOs). Their results indicated that affective evaluations of various industries were positively related to expected future returns, as well as participants' estimates of how likely they would be to invest in those industries. The authors concluded that while an investor's affective evaluation may not accurately predict future fluctuations in financial markets, it is nonetheless influential in decisions related to unfamiliar financial assets. Other evidence suggests consumers may be less likely to use affect in uncertain contexts such as the evaluation of new products. For example, in their studies, Greifeneder et al. (2011) found that participants were more likely to rely on their feelings when making fairness judgments under conditions of greater personal certainty. However, participants relied on more analytical processes when faced with greater personal uncertainty. Thus, both analytical and affective process have been suggested to dominate when consumers are faced with uncertainty.

In three experiments we address the extent to which feelings dominate early evaluations of new products. We begin by demonstrating that judgments of risk and benefit are connected in the minds of consumers. In the first two studies we adapt paradigms that have been used to study judgments of known social hazards (Finucane, et al., 2000). The results of these studies demonstrate that a greater reliance on affective processes correspond to a stronger relationship between risk and benefit judgments. 
Further, information about one attribute (e.g. benefits) can influence judgments of the other, unrelated attribute (e.g. risks). Finally, in our third study we demonstrate that by manipulating the favorability of a new product, risk and benefit judgments change in a systematic manner consistent with the affect heuristic. Together these findings suggest that feelings provide important information for early evaluations of new products.

\section{Study 1}

In our first study participants were assigned to one of three decision conditions intended to either (1) encourage reliance on affect, (2) serve as a control condition or (3) encourage cognitive deliberation. Previous research has suggested that when individuals are forced to make decisions with fewer cognitive resources available, they tend to favor heuristic decision making strategies (Payne et al., 1988) because they are more efficient. Therefore, this study included a working memory load condition that was intended to constrain cognitive resources and was expected to bias participants towards relying on affect as a heuristic when forming their judgments. In a second, control condition, participants were not given any additional instructions, and made formed judgments using whatever processes they would normally select. Finally, in a third condition participants were instructed to evaluate each innovation by listing and assigning weights to the risks and benefits associated with each product in an effort to encourage cognitively formed judgments.

We expect that consumers use affect when evaluating the risks and benefits of product innovations. Therefore, we expect participants to indicate that those innovations that they like carry few risks and many benefits relative to innovations they dislike. This reliance on affect is expected to be attenuated in the cognitive decision making condition. 
When participants are encouraged to cognitively elaborate on the risks and benefits the difference between the two judgments is expected to be smaller, and the relationship between the two weaker, than the risk and benefit judgments of those participants in the working memory load condition. This weaker association and smaller difference would indicate that judgments of risk and benefit were formed from different sources of information. This study did not consider the "real-world" relationship between risk and benefit for the product innovations. The information provided to participants in all conditions was the same. Thus, any variance in risk and benefit perception between conditions was due to differences in processing styles.

\section{Methodology}

Participants $(N=150)$ were randomly assigned to one of three decision conditions: Working Memory (WM) Load, Control or Cognitive. Each participant evaluated a random selection of six (out of 16 possible) products.

\section{Procedure}

Sixteen product innovations were selected for this study and are shown in appendix A. Participants were assigned to one of three conditions. One group of participants was placed under a working memory load immediately before evaluating each product innovation. This was accomplished by asking participants to remember a nine-digit number (e.g., "Please remember the following number. Do not write anything down, try to remember the number in your head: 762714112”) while they evaluated each product (for an example see: Shiv and Huber, 2000). Participants in the control condition were simply asked to evaluate each product without further instructions. Finally, participants in the cognitive condition were asked to generate a list of the risks and 
benefits associated with each innovation and then rank each before making summary judgments of the product's risks and benefits (order counterbalanced).

After being presented with a picture and brief description of each product, participants (depending on their condition) were asked to "choose a point on the scale that best matches your opinion of the innovation you just saw." To capture affective responses to the product innovations, participants evaluated the favorability of each innovation on a three item 11-point scale (I dislike it/ I like it, Bad/Good, Unfavorable/Favorable). Judgments of risk for each product were collected on an 11point scale anchored by "Very Risky" and "Not at All Risky." Judgments of benefits were also measured on an 11-point scale anchored by "Very Beneficial" and "Not at All Beneficial." After providing their judgments of each product, participants in the working memory load condition were asked to recall the nine-digit number.

\section{Results}

Means and standard deviations for all dependent variables are listed in table 1. Correlations between risk and benefit, across subjects for each innovation and within each condition are shown in table 2 . In the cognitive condition, the relationship between risk and benefit judgments was expected to be weaker, and the absolute difference between the two judgments expected to be smaller, than those participants who provided judgments under a working memory load. The results supported this hypothesis. The average correlation between risk and benefit ratings across innovations for the cognitive condition was -.22 . In the control condition, the average correlation between risk and benefits was -.42 , which was stronger than the cognitive condition $(z=3.24, p<.01)$. Finally, in the working memory load condition, the correlation between risk and benefit 
judgments across innovations was -.43, which was greater than the measured risk/benefit correlation in the cognitive condition, but not significantly different than the correlation between the two variables in control condition $(z=-.21, p<.41)$.

A mixed model analysis indicated that participants favorability evaluations differed between conditions $(\mathrm{F}(2,1487)=3.37, \mathrm{p}=.04)$. Overall, participants provided less favorable evaluations of innovations after listing risks and benefits in the cognitive condition $\left(M_{\text {Cognitive }}=7.60\right)$ than they did in the control condition $\left(M_{\text {Control }}=7.93\right)$ or the working memory load condition $\left(M_{\mathrm{WM} \mathrm{Load}}=7.98 ; t(1487)=2.13, p=.03 ; t(1487)=2.48\right.$, $p=.01)$. There was no difference in favorability evaluations between the control and working memory conditions $(t(1487)=.71, p>.05)$. The absolute difference between risk and benefit also differed between conditions $(F(2,1488)=3.52, \mathrm{p}=.03)$. Pairwise comparisons revealed that absolute risk/benefit differences in the control condition $\left(M_{\text {Control }}=4.06\right)$ and working memory load condition $\left(M_{\mathrm{WM} \mathrm{Load}}=4.16\right)$ were both greater than those in the cognitive condition $\left(M_{\text {Cognitive }}=3.65 ; t(1488)=2.07, p=.04 ; t(1488)=\right.$ $2.59, p=.01)$, but were not different from each other $(t(1488)=.57, p>.05)$.

The pattern of correlations between risks and benefits at an individual product level was similar. Significant negative risk/benefit relationships were observed among ten products $(63 \%)$ in the control condition and among nine products $(56 \%)$ in the working memory load condition. However, significant negative relationships were observed among only three of the product innovations (19\%) in the cognitive condition.

[Table 1 about here]

[Table 2 about here] 


\section{Discussion}

In the first study, we found support for the idea that affect may underlie early judgments of risk and benefit for novel product innovations. We expected strength of the relationship between risk and benefit judgments to differ depending on the process by which the judgments were formed. Those participants who were placed under a working memory load were expected to more heavily favor heuristic processing styles and use affect as a common basis for forming judgments of risk and benefit producing a stronger negative correlation and greater absolute risk/benefit differences. Conversely, participants assigned to the cognitive condition were expected to form judgments of risk independently from judgments of benefit, producing a weaker negative correlation and smaller absolute risk/benefit differences. This pattern of results was also observed.

The correlations among risk and benefit in the control condition were similar in strength to those in the working memory condition. This pattern of results is interesting because it suggests that the default process used by study participants to form judgments of product attributes was more similar to that used when cognitive resources are constrained (WM load condition) than to a more cognitive process of forming judgments. Such an explanation is compatible with other research suggesting that automatic, intuitive, heuristic decision making styles often function as the default when establishing evaluative judgments (Kahneman, 2011, Pham et al., 2001).

\section{Study 2}

Our second study further examines the role of the affect heuristic in forming judgments of risk and benefit. Participants in this study were asked to evaluate a series of innovations twice. After the first evaluation, participants were given information about 
either the risks or benefits associated with each innovation. Then, participants were asked to re-evaluate the products. The study was designed to test if the provision of information alters consumer judgments of the non-manipulated attribute in an affectively congruent manner. Such affectively congruent changes would indicate that judgments of risk or benefit are not considered independently, but rather based on overall affective evaluations of the innovation.

If affect functions as a common source of information when forming judgments, than information that serves to change judgments of risk or benefit should result in an affectively congruent shift in the non-manipulated attribute. For example, an affect heuristic would predict that providing information that reduces the risk of adopting an innovation should produce a positive affective response (i.e. increased favorability). When used as a source of information, this positive affect should subsequently increase judgments of the innovation's benefits. Alternatively, if the information provided serves to heighten the perceived riskiness of adopting an innovation, a consumer should experience negative affect (i.e. decreased favorability). When consulted, this negative affect should lead to a diminished evaluation of the product's benefits. A similar inverse pattern could be expected from judgments of risk if the consumer was provided information about the benefits of a product. Thus, we expect manipulations to one attribute to produce changes to another, unrelated attribute, because both are based upon a common affective source.

\section{Methodology}

Participants $(N=150)$ were randomly assigned to one of four information conditions (high-risk, low-risk, high-benefit, low-benefit) and evaluated three different 
innovations (Power Mat, Vaccine Strips, Simple GPS) in a pretest-posttest design. Several unrelated studies served as filler tasks separating the pre- and posttest measures. Procedure

During the initial presentation, each participant was presented with a picture and a brief description of each innovation (see descriptions in appendix A) in a randomized order. After viewing each innovation, participants completed the set of measures that were used in study 1 . Participants then completed approximately 30 minutes of filler tasks. After completing the filler tasks, participants received the following instructions: "The subsequent page contains some general information about the risks (benefits) associated with each of several innovations. Even though it is recognized that there are also some benefits (risks) associated with these products, these will not be dealt with at this time." Following the instructions, subjects were presented with a picture and description of each innovation for a second time (in a randomized order) along with additional information intended to influence their evaluations of either risks or benefits, depending upon the condition to which they were assigned (see appendix B for each condition). This information was written so that it did not contain any information about the non-manipulated attribute. After being presented with information about the risks or benefits of each innovation, participants evaluated each a second time using the same measures.

Results

Separate mean values were calculated for risk and benefit ratings across participants for each innovation. From these values, a mean difference measure was calculated which was then divided by the standard error of the mean difference measure 
to produce a $t$-value for both the manipulated and non-manipulated attributes. Figure 1 provides a plot of these values.

The plotted $t$-values (see figure 1) demonstrate a clear negative relationship between changes in the manipulated and non-manipulated attributes. The overall correlation of the 12 points plotted in figure 1 was -.87 . As expected the results suggest that perceptions of risk and benefit were not judged independently. Of the 12 sets (three innovations $\mathrm{x}$ four conditions) of $t$-values, 10 evidenced changes in both the manipulated and non-manipulated variables in the directions expected. That is, manipulations to either risk or benefit produced affectively congruent changes to the other, non-manipulated attribute. Within the two sets of $t$-values that did not change in the direction expected (Power Matt/high-benefit and Vaccine Strips/low-benefit), the manipulated attribute (benefit for both) did not change significantly $(t(36)=.98, p=.34$ and $t(39)=-.55, p=$ .58 respectively) between the two measurement occasions. That is, manipulations intended to alter perceptions of benefits did not produce changes as expected. However, the non-manipulated attribute (risk) in both of these conditions did change significantly $(t(36)=-2.24, p=.03$ and $t(39)=4.60, p<.01$ respectively), in a direction that was opposite that which was anticipated, but which was affectively congruent with the directional changes observed in the manipulated attribute. This again is evidence that participants consulted their feelings as a common source of information when determining their judgments rather than forming judgments of risk and benefit independently. 
A second method of analyzing the data from study 2 examined individual participant reactions to the manipulations. Tables 3 and 4 summarize these reactions. The bottom row of table 3 shows that the manipulation functioned as expected in $59.1 \%$ of trials (e.g., a subject who received information intended to increase perceptions of risk indicated higher perceived risk at time 2 than at time 1), produced no change in $14.2 \%$ of the trials, and produced an effect that was opposite what was expected in $26.7 \%$ of trials (e.g. a subject who received information intended to increase perceptions of risk indicated lower perceived risk at time 2 than at time 1). The high-risk manipulations were among the most successful with the manipulation acting to increase risk in $75.2 \%$ of trials. In contrast, the high-benefit conditions were the least successful, producing an increase in benefit judgments in $42.7 \%$ of trials. The success rates of the manipulations were similar across each of the three innovations.

The effects of risk and benefit information on the non-manipulated attributes are shown in table 4 . In $59.1 \%$ of instances in which the manipulation worked as expected (from table 3), the non-manipulated attribute changed in an affectively congruent direction $62.4 \%$ of the time. Thus, in the majority of cases in which the manipulation worked as intended (e.g., information intended to increase perceptions of risk actually led to increases in risk perceptions), the non-manipulated attribute (e.g., benefit) changed in a direction opposite that of the manipulated attribute (e.g., perceptions of benefits decreased). An additional $20.7 \%$ of these cases produced no change in the nonmanipulated attribute. In only $16.9 \%$ of cases did participants indicate that the nonmanipulated attribute changed in the same direction as the manipulated attribute (opposite of what was predicted). 
When the presentation of information failed to produce an effect on the manipulated attribute (no change, row 2 of table 4), the non-manipulated attribute should remain constant or be equally as likely to change in either direction. This pattern was observed. The percentage of cases in which the non-manipulated attribute did not change $(31.3 \%)$, changed as expected $(39.1 \%)$, or moved in a direction that was opposite expectations $(29.7 \%)$ was relatively similar.

Finally, in those instances in which the manipulated attribute changed in a direction that was contrary to the manipulation (e.g., judgments of risk decreased in response to information intended to increase perceptions of risk), the non-manipulated attribute was found to have changed in the predicted direction only $30.8 \%$ of the time (judgments of benefits decreased in the example above). Comparing this value to that of the cell in the first column and first row of table $4(62.4 \%)$, it is apparent that the values are starkly different. Overall, the non-manipulated attribute was more likely to move in a manner inverse to changes in the manipulated attribute even in those instances in which the manipulation did not function as expected. In $51.7 \%$ of trials, the non-manipulated attribute moved inversely (but affectively congruently) to the manipulated attribute, even though the manipulation produced an effect contrary to the intentions of the study (see row 3 , column 2 in table 4 ).

[Insert table 3 about here]

[Insert table 4 about here]

\section{Discussion}

Overall, the results of study 2 provide additional support for the use of the affect heuristic in consumer evaluations of innovations. Information that changed judgments of 
one attribute (e.g. greater beneficial) also produced inverse changes to another attribute (e.g. reduced risk). Changes in the non-manipulated attribute commonly occurred in a direction affectively congruent with changes in the manipulated attribute. This pattern was found even among instances in which the manipulation did not function as expected. The results diverge from what would be expected if consumer judgments of these attributes were derived only from a cognitive consideration of the information provided and suggests that participants consulted their overall affective experience regarding each product innovation to infer judgments of risk or benefit.

The $t$-values plotted in figure 1 demonstrated the strong inverse relationship between risk and benefit across conditions and innovations. At the individual level, the inverse risk/benefit relationship was more apparent. Successful manipulations of either risks or benefits produced inverse changes in the non-manipulated attribute. When manipulations produced changes that were opposite of what was intended, this inverse relationship still held. In their study of non-novel social hazards, Finucane, et al. (2000) used a similar paradigm and found support for the relationships observed in the present study. For example, in the present study the manipulations worked in more instances $(59 \%$ versus $50 \%)$. Further, the non-manipulated attribute changed in an affectively congruent direction in a greater number of instances in the present study $(62 \%$ versus $45 \%$ among instances in which the manipulation worked as expected and $52 \%$ versus $33 \%$ among those instances in which the manipulation produced an opposite change than expected).

The findings from study 2 are important because they demonstrate a causal, inverse relationship between judgments of an innovation's risks and benefits that is 
congruent with the use of the affect heuristic. Study 3 seeks to further demonstrate this relationship by manipulating favorability rather than risk or benefit.

\section{Study 3}

In study 3, we sought to manipulate affective responses to an innovation without providing risk or benefit information. Before participants began this study, they were informed that the majority of participants from an earlier data collection had indicated that they liked (disliked) each of the innovations they were about to see. This manipulation was selected because it did not convey any information about the risks and benefits associated with the products. Past research indicates that providing information about how others evaluate a target can influence consumer preferences (Burnkrant and Cousineau, 1975, Morwitz and Pluzinski, 1996). Thus, participants who were instructed that previous participants liked the innovations were expected to like the products more than participants who were instructed that previous participants disliked the innovations. This information was expected to influence study participant's affective evaluation of the products and correspondingly produce affectively congruent changes in judgments of both risk and benefit. A control condition was also included in which participants were not provided any information about other student's preferences.

This study tests a theoretical extension of the affect heuristic. We predict that, at an individual level, positive feelings in response to an innovation should correspond with higher ratings of benefit and lower ratings of risk compared to more neutral feelings. Assuming this relationship holds, it would follow that an increasingly intense affective response toward an innovation (good/bad) should strengthen the negative relationship between risk and benefit judgments. Accordingly, this relationship would be attenuated in 
the presence of neutral affective responses (e.g., neither like nor dislike). In other words, increasingly strong evaluations (e.g., I love it!) should correspond with more polarized judgments of risk and benefit (e.g., benefit is very high, risk is very low).

\section{Methodology}

Participants $(N=42)$ were assigned one of the three instruction conditions (favorable, control or unfavorable) and evaluated the three product innovations (tricycle, dog bowl and fruit bowl) presented in random order.

\section{Procedure}

Depending on their condition, participants were instructed: "In this study we are interested in your opinions of new products and concepts. On the following screens you will be presented with 3 different new products that were favorably (unfavorably) evaluated in a previous study similar to this one. In that study, the majority of participants indicated that they liked (disliked) each of these products. Please answer the questions to the best of your ability." Participants in the control condition were not given any information about other participants who may have evaluated the products and were simply told that they would be presented with three products and asked to give their opinion of each. After reading the instructions, participants were presented the innovations and asked to evaluate each using the measures from the first study. Results

The results of study 3 are shown in table 5. An ANOVA analysis indicated differences in overall evaluations by condition $(F(2,39)=4.31, p=.02)$. Planned contrasts revealed that the overall evaluations of participants assigned to the favorable instruction group $\left(M_{\text {favorable }}=8.30\right)$ and the control group $\left(M_{\text {control }}=8.06\right)$ were more 
favorable than those assigned to the unfavorable instruction group $\left(M_{\text {unfavorable }}=6.74\right.$; $t(39)=2.90, p=.01)$. The mean evaluation for participants who were told that previous study participants disliked the innovations was near the midpoint of the scale (six on an 11-point scale). No statistical difference in overall evaluations was observed between those assigned to the favorable condition and those in the control condition $(t(39)=.46, p$ $>.05)$. Thus, the average evaluation of those who were provided negative information is best characterized as neutral rather than negative, whereas those participants assigned to the other two conditions held favorable evaluations. ${ }^{1}$

The affect heuristic predicts that more extreme affective responses should correspond to a stronger negative relationship between risks and benefits. To test this hypothesis, a measure of the difference between risk and benefit for each innovation was calculated and then averaged across products. Greater differences between risk and benefit were expected to correspond with more affectively extreme evaluations. An ANOVA revealed significant differences in this risk-benefit difference score among instruction conditions $(F(2,39)=12.95, p<.01)$. Planned contrasts revealed that the riskbenefit difference scores for those participants who were told that previous study participants liked the innovations $\left(M_{\text {favorable }}=-4.38\right)$ and those assigned to the control condition $\left(M_{\text {control }}=-4.04\right)$ was larger than the scores of those participants who were instructed that previous study participants did not like the innovations $\left(M_{\text {unfavorable }}=.67\right.$, $t(39)=5.08, p<.01)$. However, the difference scores of the control group did not differ from those of the favorable instruction group $(t(39)=.33, p>.05)$. Similarly, risk judgments were lower and benefit judgments higher in the favorable and control

\footnotetext{
${ }^{1}$ This analysis was also conducted using a repeated measures ANOVA. The results of that analysis indicated within subjects differences in evaluations of the innovations (the tricycle was preferred over the other two innovations), but no interaction between the different innovations and instructional conditions.
} 
conditions relative to the unfavorable condition $(t(39)=5.35, p<.01 ; t(39)=2.77, p<$ $.01)$. These results reflect the observed differences in participant's overall evaluation of these innovations and suggest that study participants were using this evaluation to inform judgments of risk and benefit. Those conditions that produced more extreme overall evaluations (favorable information and control conditions) also produced greater differences in judgments of risk and benefit. Conversely, when participants were provided with unfavorable information, their evaluation of the innovations was less positive (almost neutral) and the perceived difference between risk and benefit was attenuated.

[Insert table 5 about here]

\section{Discussion}

The results of study 3 again suggest that the affect heuristic influences risk and benefit judgments of product innovations. More extreme evaluations were shown to correspond with greater differences between risk and benefit judgments. This relationship can be explained by study participants basing these judgments on their underlying affective response to the products, rather than available information about each. The instructions provided to participants acted to increase or decrease overall favorability but were devoid of information about the risks and benefits associated with the product. The manipulations achieved their purpose of producing variations in overall evaluations but must be interpreted with respect to the scaling of favorability evaluations. Participants from the control condition and those who were provided with positive information provided similarly favorable evaluations (e.g. "I like it") of the innovations. The observation that members of the control group also provided favorable evaluations is 
reflective of a known pro-innovation bias, whereby innovations are often perceived as inherently favorable (Rogers, 1976). As predicted by the affect heuristic, sizable differences between judgments of risk and benefit were found among participants in these two groups. In contrast, participants who were provided with negative information indicated less favorable (almost neutral) evaluations of the innovations. As expected, this indifferent summary judgment was associated with judgments of nearly equivalent amounts of risk and benefit associated with the products, evidenced by a low mean difference score. This shift in the pattern of judgments suggests that participant's were basing their judgments of risk and benefit on affect experienced in response to the product innovations.

\section{General Discussion}

This research intended to investigate the use of the affect heuristic in early consumer evaluations of product innovations. Extant literature characterizes consumer risk assessment of innovations as primarily an analytical consideration of the information at hand. However, the results of these studies demonstrate that a consumer's feelings may also influence their judgments. Judgments of both risk and benefit were shown to be interrelated and the pattern of results is consistent with the affect heuristic. The negative risk/benefit relationship discussed by Alhakami and Slovic (1994) and Finucane, et al. (2000) was also found among an assortment of product innovations, individuals and manipulations.

The first study established that judgments of risk and benefit associated with product innovations were negatively related. Further, more cognitive decision processes were found to weaken this negative relationship. The second study provided additional 
evidence that affect serves as a common basis for judgments of risk and benefit. Manipulations that influenced judgments of one attribute (e.g., increases in risk perception) were shown to also influence non-manipulated attributes (e.g., decreases in benefit) in an affectively congruent manner. Finally, the results of the third study supported a theoretical extension of the affect heuristic by demonstrating that stronger overall evaluations corresponded with greater differences in perceptions of risk and benefit. More favorable evaluations were found to correspond with greater differences in risk and benefit whereas more neutral evaluations were associated with smaller differences.

Together, these studies contribute to both our theoretical understanding of how consumers form early evaluations of innovations and attest to the generalizability of the affect heuristic. Product innovations are marked by uncertainty both about the risks and benefits offered by a product. The studies presented above provided evidence that in many cases, affect is used to infer judgments of these attributes. While we acknowledge that consumers may come to understand the risks involved in adopting an innovation by carefully gathering information before arriving at a judgment. The results of the current studies also suggest that a person's feelings about an innovation are likely to influence their perceptions of risk.

This research makes an additional contribution by demonstrating that the affect heuristic extends to consumer evaluations of product innovations. Such an extension should not be dismissed as a replication of existing research. The innovations used as stimuli in these studies were novel products that participants had never encountered before and thus had no previously formed evaluations upon which to draw. Past research 
has suggested that feelings are often instantiated upon exposure to a stimulus and are not dependent upon the retrieval of cognitively formed evaluations (Pham, et al., 2001). The results of the current studies support this assertion. Additionally, unlike earlier research (Finucane, et al., 2000) participants in each of the studies were asked to make risk and benefit evaluations of specific products, as opposed to broad social hazards and they were also asked to consider these evaluations from their own perspective, rather than from the prospective of society as a whole. These conditions more closely match the types of judgments people make in the marketplace. The finding that these effects extend to such contexts underscores the importance of the affect heuristic in judgment and decision making more generally.

For practitioners, the results of these studies highlight the importance of considering affective decision making styles in consumer evaluations of new products. The affect heuristic helps to address several important issues confronting marketers. First, the affect heuristic suggests an explanation for why first impressions are so important. Based on the findings above, failing to create a favorable affective evaluation during the launch of a new product will likely bias subsequent evaluations of the product's attributes. Disliking a new product leads to inferences that the product is risky and offers little benefit. Similarly for market researchers testing product concepts, these findings provide an explanation for why consumers often find it difficult to objectively evaluate really new products (Hoeffler, 2003). Rather than forming judgments by carefully analyzing the attributes of a product, the affect heuristic suggests that consumers may look at their initial affective experience, and then pattern their responses in an affectively congruent fashion. If so, marketers testing new product concepts should be aware that a 
concerted effort may be required in order to get research participants to cognitively evaluate a new product concept.

This research also suggests how some product attributes can compensate for others. The affect heuristic centers on the idea that affect serves as a common source of information for evaluative judgments of an object's attributes. Thus, specific risks (or benefits) of a product are likely to be overlooked if the overall evaluation is favorable. For marketers, this distinction carries real consequences. In the second and third studies, judgments of an innovation's attributes were shown to be connected to the overall evaluation of the product. This implies that communications emphasizing attributes that serve to increase the overall favorability of a product (e.g., increase perceptions of benefits), could be expected to produce affectively congruent changes in evaluations of attributes which may be completely unrelated (e.g., decrease perceptions of risk). For example, public health campaigns tasked with increasing the perceived risk associated with cigarette smoking could choose to focus on decreasing the perceived benefits associated with smoking (e.g. stress relief, popularity, etc.). As shown in study 2, this information would be expected to decrease the favorability of smoking and thus, increase perceptions of risk even without addressing the risks directly. Such possibilities represent fruitful opportunities for future research. 


\section{References}

Ajzen, I. 1991. The theory of planned behavior. Organizational Behavior and Human Decision Processes 50(2): 179-211.

Alexander, D.L., Lynch, J.G. and Wang, Q. 2008. As Time Goes By: Do Cold Feet Follow Warm Intentions for Really New Versus Incrementally New Products? Journal of Marketing Research 45(3): 307-319.

Alhakami, A. and Slovic, P. 1994. A Psychological Study of the Inverse Relationship Between Perceived Risk and Perceived Benefit. Risk Analysis 14(6): 1085-1096.

Arts, J.W.C., Frambach, R.T. and Bijmolt, T.H.A. 2011. Generalizations on consumer innovation adoption: A meta-analysis on drivers of intention and behavior. International Journal of Research in Marketing 28(2): 134-144.

Bechara, A., Damasio, H. and Damasio, A.R. 2000. Emotion, Decision Making and the Orbitofrontal Cortex. Cerebral Cortex 10(3): 295-307.

Burnkrant, R.E. and Cousineau, A. 1975. Informational and Normative Social Influence on Buyer Behavior. Journal of Consumer Research 2(3): 206-215.

Castaño, R., Sujan, M., Kacker, M. and Sujan, H. 2008. Managing Consumer Uncertainty in the Adoption of New Products: Temporal Distance and Mental Simulation. Journal of Marketing Research 45(3): 320-336.

Cohen, J., Pham, M. and Andrade, E. 2008. The Nature and Role of Affect in Consumer Behavior. Handbook of Consumer Psychology: 197-348.

Damasio, A.R. 2000. Descartes' Error: Emotion, Reason, and the Human Brain. New York: Quill.

Davis, F.D. 1989. Perceived Usefulness, Perceived Ease of Use, and User Acceptance of Information Technology. MIS Quarterly 13(3): 319-340.

Duckworth, K.L., Bargh, J.A., Garcia, M. and Chaiken, S. 2002. The Automatic Evaluation of Novel Stimuli. Psychological Science 13(6): 513-519.

Feldman Barrett, L. and Salovey, P. 2002. The Wisdom in Feeling: Psychological Processes in Emotional Intelligence. New York: Guilford Press.

Finucane, M., Alhakami, A., Slovic, P. and Johnson, S. 2000. The Affect Heuristic in Judgments of Risks and Benefits. Journal of Behavioral Decision Making 13(1): 1-17.

Fishbein, M. and Ajzen, I. 1975. Belief, Attitude, Intention and Behavior: An Introduction to Theory and Research. Reading, MA: Addison-Wesley. 
Ganzach, Y. 2000. Judging Risk and Return of Financial Assets. Organizational Behavior and Human Decision Processes 83(2): 353-370.

Gatignon, H. and Robertson, T.S. 1991. Innovative Decision Processes. In: Handbook of Consumer Behavior. Thomas S. Robertson and Harold H. Kassarjian (eds.). Englewood Cliffs, NJ: Prentice-Hall, pp. 316-348.

Gorn, G.J., Goldberg, M.E. and Basu, K. 1993. Mood, Awareness, and Product Evaluation. Journal of Consumer Psychology 2(3): 237.

Greifeneder, R., Müller, P., Stahlberg, D., Van Den Bos, K. and Bless, H. 2011. Guiding trustful behavior: The role of accessible content and accessibility experiences. Journal of Behavioral Decision Making 24(5): 498-514.

Hauser, J.R., Tellis, G.J. and Griffin, A. 2006. Research on innovation: A review and agenda for marketing science. Marketing Science 25(6): 687-717.

Herzenstein, M., Posavac, S.S. and Brakus, J.J. 2007. Adoption of New and Really New Products: The Effects of Self-Regulation Systems and Risk Salience. Journal of Marketing Research 44(2): 251-260.

Hinson, J., Jameson, T. and Whitney, P. 2002. Somatic markers, working memory, and decision making. Cognitive, Affective, \& Behavioral Neuroscience 2(4): 341.

Hirschman, E.C. 1980. Innovativeness, Novelty Seeking, and Consumer Creativity. Journal of Consumer Research 7(3): 283-295.

Hoeffler, S. 2003. Measuring preferences for really new products. Journal of Marketing Research 40(4): 406-420.

Jansson, J., Marell, A. and Nordlund, A. 2011. Exploring consumer adoption of a high involvement eco-innovation using value-belief-norm theory. Journal of Consumer Behaviour 10(1): 51-60.

Kahneman, D. 2003. A perspective on judgment and choice: Mapping bounded rationality. American Psychologist 58(9): 697-720.

Kahneman, D. 2011. Thinking, Fast and Slow. New York: Farrar, Straus and Giroux.

Keltner, D., Locke, K.D. and Audrain, P.C. 1993. The influence of attributions on the relevance of negative feelings to personal satisfaction. Personality and Social Psychology Bulletin 19(1): 21-29.

Lowenstein, G.F., Weber, E.U., Hsee, C.K. and Welch, N. 2001. Risk as feelings. Psychological Bulletin 127(2): 267-286.

MacGregor, D.G., Slovic, P., Dreman, D. and Berry, M. 2000. Imagery, affect, and financial judgment. Journal of Behavioral Finance 1(2): 104-110. 
Mahajan, V., Muller, E. and Bass, F.M. 1990. New Product Diffusion Models in Marketing: A Review and Directions for Research. Journal of Marketing 54(1): 1-26.

Manning, K.C., Bearden, W.O. and Madden, T.J. 1995. Consumer Innovativeness and the Adoption Process. Journal of Consumer Psychology 4(4): 329.

Moreau, C.P., Lehmann, D.R. and Markman, A.B. 2001. Entrenched Knowledge Structures and Consumer Response to New Products. Journal of Marketing Research 38(1): 14-29.

Morwitz, V.G. and Pluzinski, C. 1996. Do Polls Reflect Opinions or Do Opinions Reflect Polls? The Impact of Political Polling on Voters' Expectations, Preferences, and Behavior. The Journal of Consumer Research 23(1): 53-67.

Nakata, C. and Weidner, K. 2012. Enhancing New Product Adoption at the Base of the Pyramid: A Contextualized Model. Journal of Product Innovation Management 29(1): 21-32.

Ostlund, L.E. 1974. Perceived Innovation Attributes as Predictors of Innovativeness. Journal of Consumer Research 1(2): 23-29.

Payne, J.W., Bettman, J.R. and Johnson, E.J. 1988. Adaptive strategy selection in decision making. Journal of Experimental Psychology: Learning, Memory, and Cognition 14(3): 534-552.

Pham, M.T. and Avnet, T. 2009. Contingent reliance on the affect heuristic as a function of regulatory focus. Organizational Behavior and Human Decision Processes 108(2): 267-278.

Pham, M.T., Cohen, J.B., Pracejus, J.W., Hughes, D.G., Mick, D.G. and Baumgartner, H. 2001. Affect Monitoring and the Primacy of Feelings in Judgment. Journal of Consumer Research 28(2): 167-188.

Ram, S. and Sheth, J.N. 1989. Consumer Resistance to Innovations: The Marketing Problem and its Solutions. Journal of Consumer Marketing 6(2): 5-14.

Rogers, E.M. 1976. New Product Adoption and Diffusion. The Journal of Consumer Research 2(4): 290-301.

Rogers, E.M. 2003. Diffusion of Innovations. New York, NY: The Free Press.

Schwarz, N. and Clore, G.L. 1983. Mood, misattribution, and judgments of well-being: Informative and directive functions of affective states. Journal of Personality 45(3): 513 523.

Schwarz, N. and Clore, G.L. 1988. How do I Feel About It? Informative Functions of Affective States. In: Affect, Cognition, and Social Behavior. K. Fielder and J. Forgas (eds.). Toronto: Hogrefe International, pp. 44-62. 
Schwarz, N. and Clore, G.L. 2007. Feelings and phenomenal experiences. In: Social Psychology: Handbook of Basic Principles. Arie W. Kruglanski and E. Tory Higgins (eds.), pp. 385-407.

Sheppard, B.H., Hartwick, J. and Warshaw, P.R. 1988. The theory of reasoned action: A meta-analysis of past research with recommendations for modifications and future research. Journal of Consumer Research: 325-343.

Sheth, J.N. 1981. Psychology of Innovation Resistance: The Less Developed Concept (LDC) in Diffusion Research. In: Research in Marketing. Jagdish N. Sheth (ed.). Greenwich, CT: JAI Press, pp. 273-282.

Shiv, B. and Huber, J. 2000. The Impact of Anticipating Satisfaction on Consumer Choice. Journal of Consumer Research 27(2): 202-216.

Slovic, P., Finucane, M., Peters, E. and MacGregor, D. 2002. The Affect Heuristic. In: Heuristics and biases: The psychology of intuitive judgment. T Gilovich, D Griffin and D Kahneman (eds.): Cambridge University Press New York, pp. 397-420.

Steenkamp, J.B. and Gielens, K. 2003. Consumer and Market Drivers of the Trial Probability of New Consumer Packaged Goods. Journal of Consumer Research 30(3): 368-384.

Veryzer Jr, R.W. 1998. Key factors affecting customer evaluation of discontinuous new products. Journal of Product Innovation Management 15(2): 136-150.

Wood, S.L. and Moreau, C.P. 2006. From Fear to Loathing? How Emotion Influences the Evaluation and Early Use of Innovations. Journal of Marketing 70(3): 44-57.

Wood, S.L. and Swait, J. 2002. Psychological Indicators of Innovation Adoption: CrossClassification Based on Need for Cognition and Need for Change. Journal of Consumer Psychology 12(1): 1-13. 